\title{
A ProteÇÃo da Liberdade e o CONTROLE SANITÁRIO ${ }^{* *}$
}

\author{
THE PROTECTION OF LIBERTY AND THE SANITARY CONTROL
}

Herbert Cornelio Pieter de Bruyn Jr. ${ }^{(*)}$

\section{RESUMO}

O presente texto aborda a aparente contradição entre a idéia de liberdade e o direito à saúde, em especial quando traduzida por meio das ações de vigilância sanitária. Procura-se demonstrar, ao fim, a real possibilidade de harmonizarem-se os valores envolvidos nesse confronto, bem como o modo de os efetivarem, sob o ângulo jurídico, como forma de assegurar o postulado da dignidade da pessoa humana. Para esse intento, esboça-se uma análise do conceito de liberdade, quer sob o prisma filosófico, quer sob o jurídico, com o escopo de retratar como a mutação do seu significado ao longo do tempo e, portanto, a sua relatividade ajudam a fixar a exata dimensão dos direitos sociais, dentre os quais o direito à saúde, desenvolvidos em torno da idéia de igualdade. Faz-se, outrossim, uma digressão sobre os aspectos históricos e constitucionais envolventes da idéia de Estado de Direito e Estado Social e Democrático de Direito, aspirante à redução da complexidade do mundo na Constituição, além da análise das ações de vigilância sanitária nesses dois contextos, de forma a demonstrar o alargamento do campo de ação do poder de polícia e seu significado no mundo contemporâneo.

\section{Palavras-chave}

Liberdade, Direito à Saúde, Vigilância Sanitária.

(*) Palestra proferida por ocasião do VI Seminário Internacional de Direito Sanitário, em $1^{2}$ de outubro de 2002, no auditório da Faculdade de Saúde Pública da USP, em São Paulo.

$\left(^{* *}\right)$ Juiz Federal da 3* Vara em Santos; Professor de Direito do Estado e Fiscal no curso de PósGraduação da Universidade São Judas (São Paulo), Professor de Direito Financeiro e Tributário da Unicapital (São Paulo), Mestrando em Direito Constitucional (PUC/SP), Especialista em Direito Público (PUC/SP), em Direito Aduaneiro (Escola Superior de Administração Fazendária) e em Direito Tributário (CEEU). 


\section{ABSTRACT}

The following text concerns the apparent contradiction between the idea of liberty and the right to health especially when it is presented through actions of sanitary surveillance. The purpose of this text is to demonstrate the real possibility of harmonizing the values enrolled in this confrontation, as well as the way of accomplishing them, under the legal view, as a way to guarantee the postulate of the human being dignity. For this purpose, an analysis of the concept of liberty is made, whether under a philosophical view or a legal view, aiming to demonstrate how the mutation of its meaning along time and, therefore, its relativity help to set the exact dimensions of the sociai rights, among these the right to health, developed according the idea of equality. It is also made a digression about the historical and constitutional as. pects that surround the idea of State of Law and Social and Democratic State of Law, as well as an analysis of the sanitary surveillance on these two contexts, in order to demonstrate the enlargement of the action field of the police power and its meaning in the contemporary world.

\section{Keywords}

Liberty, Right to health, Sanitary Surveillance.

\section{INTRODUÇÃO}

Partindo da análise histórica e filosófica do conceito de liberdade, confrontada com a prática político-constitucional de ao menos dois períodos fundamentais na formação do mundo contemporâneo, objetiva este estudo fincar as bases sobre as quais se deve exercer o poder de polícia inerente às ações de vigilância sanitária, estabelecendo-se, para isso, como eixo central da obra, as implicações decorrentes da colisão entre os valores liberdade e solidariedade ou liberdade e igualdade material.

Pretende-se, ao fim, não só contribuir para a literatura jurídica pertinente ao tema - relativamente escassa -, como, outrossim, propiciar aos aplicadores do Direito, sejam juristas ou técnicos sanitaristas, instrumentos de reflexão para suas ações e decisões nesta área.

Obviamente, não se pretende esgotar o assunto que, rico e complexo, extravasa os limites desse trabalho. Almeja-se, apenas, dar suporte às ponderações formuláveis quando, diante da necessidade de assegurar-se o efetivo gozo do direito constitucional à saúde, aventam-se quais os limites da liberdade, decerto não inteiramente solapável. Nesse ponto, surge a questão do justo equilíbrio entre a liberdade e o direito social à saúde. 
A Constituição ultrapassa o texto formal, de caráter jurídico e político nela plasmado. Consubstancia o sistema de valores vigentes na sociedade, incorporados às normas jurídicas, que, por serem cogentes, se distanciam dos programas preconizados pelo Estado ou pela sociedade.

Nesse contexto, certamente a solução do problema estará, em face do fato concrato, na ponderação dos diversos valores expostos na Lei Fundamental, a cietivar-se mediante a observância aos princípios da razoabilidade e da proporcionalidade, implícitos na Constituição.

Esse, pois, é o escopo do trabalho e sua linha mestra de raciocínio, como, a seguir, procura-se demonstrar.

\section{DO TEMA}

Tendem os pensadores atuais, dentre os quais Edgar Morin, a assinalar a crescente complexidade do mundo atual, freqüentemente por eles designado de pós-moderno, o qual termina por agasalhar, em seu interior, profundas contradições, nem sempre harmonizáveis de modo fácil e completo.

Isso é o que se passa com a nossa Constituição, a qual, como um reflexo da complexa sociedade deste período, consagra, simultaneamente, tanto direitos individuais, alguns até oponíveis erga omnes, como direitos sociais (coletivos ou difusos), argüíveis, certas vezes, por qualquer um da coletividade.

Até recentemente, refletindo os princípios prevalentes desde a Revolução Francesa, restringia-se a defesa dos ideais de liberdade, igualdade e fraternidade, do ponto de vista jurídico, a um conteúdo meramente formal: dispensava-se o Poder Público de conquistar e assegurar as condições mínimas necessárias ao efetivo gozo dos direitos derivados desse ideário, embora consideradas imprescindíveis à dignidade humana, para a ele determinar, em linhas gerais, a manutenção da ordem interna, com o afastamento das demais espécies de demandas sociais.

Em suma, enquanto prevaleceu a clássica concepção liberal de Estado - o que ocorreu, preponderantemente, entre o final do século XVIII e a terceira década do século XX - limitava-se o papel deste, grosso modo, a assegurar a ordem interna, relegando-se à sorte e ao setor privado eventuais preocupações com outras questões sociais, por reputar-se este o mais competente para solucioná-las.

Dentro desse contexto, pois, nitidamente marcado pelo liberalismo burguês, somente as "liberdades individuais" reconheciam-se como direitos fundamentais. 
Ao vicejar, contudo, a concepção democrática e social de Estado, transmutado no principal responsável pela resolução das demandas públicas, especialmente quando vinculadas à implementação da justiça social, amplia-se o leque das funções estatais, reconhecendo-se outra categoria de direitos fundamentais, conectada a determinadas prestações do Poder Público, habitualmente dedicadas à concretização da igualdade material.

Nas Constituições dessa linha ideológica, inculca-se, como valor superior, a implementação do humanismo em sua mais alta e moderna expressão: não se trata apenas de proteger o indivíduo em face do Estado ou de terceiros capazes de com ele interagir socialmente no tocante à vida, integridade física, moral e variadas formas de liberdade (a dimensão negativa dos direitos individuais); trata-se, outrossim, de garantir reais possibilidades de fruição condigna desses bens, por via dos direitos fundamentais a prestações positivas do Estado.

Este, pode-se dizer, é o sentido de nossa Constituição quando, em seu art. 196, proclama ser a saúde direito de todos e dever do Estado, a quem incumbe a adoção de políticas sociais e econômicas tendentes à redução do risco de doenças e outros agravos, bem como impor o acesso universal igualitário às ações e serviços pertinentes à saúde pública em todos os seus níveis, preventivos e recuperatórios. ${ }^{(1)}$

Converge a Constituição, pois, não apenas com as dos demais países civilizados do globo, ${ }^{(2)}$ como, de igual forma, com os fundamentos ideológicos que a embasam, discerníveis não só em seu prólogo, afirmativo da intenção de criação de um Estado Democrático de Direito, respeitador dos direitos sociais e individuais, mas, também, em inúmeros dispositivos efetivos da Lei Superior, juridiciadores dos valores e finalidades pertinentes a essa forma de Estado.

Com efeito, ao assumir ser a dignidade da pessoa humana o valorfonte da ordem jurídica, ${ }^{(3)}$ consoante enuncia 0 inciso III do art. $1^{2}$ da nossa Constituição, que aspira, dentre outros objetivos, à conquista e manutenção do bem-estar do indivíduo na sociedade e o desta como um todo (art. $3^{\circ}$ ), compromete-se o Poder Público não somente a respeitar esse status do indivíduo, abstendo-se de praticar e impedindo posturas atentatórias aos direi-

(1) Promulgada com o intento de disciplinar o art. 196 da Constituição Federal de 1988, também a Lei n. 8.080/90, art. $2^{\circ}$, caput, assevera tratar-se a saúde de "um direito fundamental do ser humano, devendo o Estado prover as condições indispensáveis ao seu pleno exercício".

(2) Veja-se, por exemplo, o art. 43 da Constituição espanhola, de 27.12.1978, e o art. 64 da Constituição da República Portuguesa, de 2.4.1976, que reconhecem ser direito do cidadão a proteção da saúde. Na Constituição da República Federal da Alemanha, a idéia aparece implicita, com a alusão a um objetivo estatal geral concernente ao Estado de Direito Social (In HESSE, K. Elementos de Direito Constitucional da República Federal da Alemanha. Trad. Luis Afonso Heck. Porto Alegre: Fabris, 1998).

(3) Como explica REALE, aliás, ao proceder à análise da axiologia, o homem é "o valor-fonte de todos os valores" (Filosofia do Direito. 5* ed. São Paulo: Saraiva, 1969, p. 194). Desse modo, inevitavelmente, todo o Direito sobre ele alicerça-se. 
tos a ela inerentes, como, igualmente, a atuar no sentido de propiciar a efetiva fruição dos direitos fundamentais, por meio da implementação de políticas públicas e, em especial, prestações positivas, visando a concretizar os valores fundantes da sociedade. Tudo, obviamente, por meio de lei, o instrumento formal apropriado para a densificação dos direitos em questão, só vagamente expostos nas normas constitucionais.

Freqüentemente, contudo, embora pertinentes à dignidade humana, não raro revelam as aludidas categorias de direitos fundamentais, em situações concretas, a nítida contradição ideológica que as trouxe a lume: confrontados, no mundo fático, um com o outro - direitos do indivíduo e direitos da sociedade globalmente considerada -, evidentemente resulta dificultada a aplicação prática das regras voltadas à concretização do valor-fonte da ordem jurídica. Podem, afinal, não apenas estar vinculados a interesses não coincidentes, mas, muitas vezes, opostos entre si. É, enfim, o que amiúde ocorre entre o direito fundamental à liberdade, de índole individual, e o direito à saúde, de compleição social.

Não há, porém, uma total contraposição entre esses valores, capaz de levá-los a uma completa anulação: ponderando-os, é possivel equilibrá-los, viabilizando, assim, a proporcional satisfação desses paradigmas. Esta, a propósito, é a tarefa dos legisladores e do juízes, aos quais, em síntese, incumbe ponderar os valores constitucionalmente protegidos, plasmados na Constituição sob a forma de princípios jurídicos, isto é, com caráter imperativo e vinculante, ${ }^{(4)}$ e, na forma da lei, implementá-los, em consonância com a natural tarefa que lhes é acometida.

Dois pontos, portanto, ressaltam no tocante à plena possibilidade de concretização de ambas as modalidades de direitos fundamentais: um, pertinente à questão dos limites de ação das pessoas em seu recíproco convívio social; outro, referente à necessidade de uma atuação positiva do Estado, no sentido de implantar organizações e procedimentos hábeis a atender à prestação que, sob a forma de dever jurídico, é-Ihes exigida. Paralelamente, há de se aplicar os princípios da razoabilidade e da proporcionalidade, que daquele é consectário, em face dos casos concretos nos quais ocorram colisões entre essas duas dimensões de direitos.

Sobre o primeiro ponto, já Stuart Mill, em pleno apogeu do liberalismo clássico, questionava acerca dos limites da liberdade, ${ }^{(5)}$ embora se posicionasse do modo mais francamente favorável aos particulares, segundo a natural perspectiva da época. No entanto, como asseverou Benjamin Constant de Rebecque, em famosa conferência pronunciada em 1819, não há um

(4) Aponta também CANOTILHO a natureza vinculante dos direitos fundamentais, querendo representar sua indisponibilidade, no cerne essencial, destes direitos pelo legislador e a possibilidade de invocá-los contra as próprias autoridades legiferantes (Constituição Dirigente e Vinculação do Legislador. 2" ed. Coimbra: Coimbra Editora, 2001, p. 363).

(5) STUART MILL, John. "Sobre a Liberdade" (1859). 
conceito unívoco de liberdade (como reiteram inúmeros textos filosóficos a respeito). ${ }^{(6)}$ Diferia, por exemplo, o conceito de liberdade dos antigos, atrelado à autoridade da polis e das convenções sociais e religiosas, do conceito dos modernos, mais vinculada à idéia de independência do sujeito. ${ }^{(7)}$

Em outras palavras, não há um conceito único e absoluto de liberdade. Sua existência se dá, apenas, da forma como a sociedade, na sua maioria, atribui ao indivíduo em determinado contexto social. Poderá ser mais ou menos ampla; porém, nunca absoluta: tanto aparece condicionada por fatores materiais, quanto por fatores políticos, religiosos, sociológicos, psicológicos ou simplesmente biológicos, como o demonstram as mais modernas ciências.

Obviamente, isso não pode servir para que se desdenhe a liberdade, tomando-a um bem menor, circunstancial e facilmente manejável. Ao contrário: implica reconhecê-la em sua inteireza, como um legado da natureza, embora inserto dentro de um contexto maior, o qual, em síntese, podemos denominar "convívio social".

Dizia Ortega y Gasset ser o homem "forçosamente livre". Livre porque, como afirmava um provérbio indiano, onde quer que pousasse a planta do seu pé, estaria a pisar sempre mil caminhos plausíveis, ${ }^{\left({ }^{8}\right)}$ isto é, sempre há inúmeras possibilidades de ação, sobre as quais é livre para escolher. Não obstante, porém, cumpra reconhecer essa natural autonomia de decisão, ela não se apresenta desvinculada de pressões ou contingências. Pelo contrário. O homem, diz o filósofo, age premido por circunstâncias e vocações sobre as quais não the é possibilitado escolher: consubstanciam dados da natureza ou, principalmente, da sociedade, de inarredável incidência.

É dentre essas "circunstâncias" do mundo contemporâneo, pois, que se coloca a observância a determinados padrões de convívio, os quais incluem a busca de uma efetiva igualdade. Não só igualdade na lei, isto é, no tratamento legal dispensado, mas, também, em face da lei, ou seja, com a consideração da natural desigualdade (física, de oportunidades etc.) das pessoas.

Dessa forma, não basta proclamar o direito à saúde. Cumpre, outrossim, assegurá-lo, não só propiciando às elites a existência de profissionais e equipamentos aptos para tanto, mas, também, fornecendo aos hipossuficientes efetivos meios de usufruí-lo em condições idênticas àquelas asseguradas aos demais.

(6) Veja-se, a respeito, ABBAGNANO (verbete "liberdade"), BOBBIO, MATTEUCCI e PASQUINO. Dicionário de Política. $5^{\text {a }}$ ed. Brasília: UnB; São Paulo: Imprensa Oficial do Estado de São Paulo, 2000.

(7) SALDANHA, N. O Estado Moderno e a Separação de Poderes. São Paulo: Saraiva, 1987, p. 27.

(8) KUJAWSKI, Gilberto de Mello. Ortega y Gasset - A Aventura da Razão. São Paulo: Moderna, coleção Logos, 1994, p. 53. 
É, enfim, o que objetivamente pretende a Constituição e quer propiciar - ao menos sob certos aspectos - a Lei n. 8.080, de 19 de setembro de 1990, reguladora das condições para a promoção, proteção e recuperação da saúde e organização e funcionamento dos serviços correspondentes.

Segundo a Lei, "são fatores determinantes e condicionantes da saúde, dentre outros, a alimentação, a moradia, o saneamento básico, o meio ambiente, o trabalho, a renda, a educação, o transporte, o lazer e o acesso aos bens e serviços essenciais" (art. $3^{\circ}$ ).

Todos, portanto, sem olvido algum, devem ser protegidos, até mesmo porque, independentemente do seu objeto imediato, inúmeros outros dispositivos da Constituição deles tratam, direta ou indiretamente. ${ }^{(9)}$ Principalmente 0 art. $6^{\circ}$, que enumera como direitos fundamentais sociais os pertinentes à educação, saúde, trabalho, moradia, lazer, segurança, previdência social, à proteção à maternidade e à infância e à assistência aos desamparados, na forma por ela disposta.

Mostra-se amplo, portanto, o espectro de fatores sobre os quais se preocupa a Constituição, com possível repercussão na saúde, embora só sobre alguns deles debruce-se o Direito Sanitário, o complexo de normas jurídicas relativas à disciplina da ação estatal destinada à eliminação, diminuição e prevenção de riscos à saúde, inclusive mediante a intervenção em circunstâncias deles ensejadores, decorrentes do meio ambiente, da produção ou circulação de bens e da prestação de serviços de interesse da saúde (art. 6² $\S 1^{2}$, da Lei n. 8.080/90).

Os demais fatores permanecem adstritos a específicos subsistemas jurídicos e políticas públicas, muitas vezes só mediatamente relacionados à saúde pública.

Ações de vigilância sanitária, surgidas a partir da preocupação com o controle de atividades ou cidades, visando a evitar a propagação de doenças - que, em épocas passadas, ceifaram boa parcela da população da Europa ou mesmo da América(10) —, podiam ser vislumbradas já no século XVII, na

(9) Vejam-se, apenas à guisa de exemplo, os arts. $1^{2}$, III e IV (relativos à preservação da dignidade da pessoa humana e dos valores sociais do trabalho e da livre iniciativa); $3^{2}$, III e IV (pertinentes à meta de erradicação da pobreza, marginalização e desigualdade social e regional e de promoção do bem de todos sem discriminação); $5^{\circ}$, caput (sobre a inviolabilidade do direito à vida, liberdade, igualdade, segurança, propriedade), III (vedação à tortura, tratamento desumano ou degradante), $X$ (proteção à intimidade, honra e imagem), XIII (liberdade profissional), XXXII (proteção do consumidor); arts. $6^{2}$ e $7^{2}$ (direitos sociais); art. 37, diversos incisos (acerca dos servidores públicos); art. 170, IV a VIII (princípios da ordem económica) e praticamente todo o Título VIII da Constituição, pertinente à ordem social (arts. 193 a 232), dentre outros.

(10) A peste negra (bubónica), na Europa, em 1348, e as largas e intermitentes epidemias de sarampo, varíola, gripe e peste verificadas na América espanhola, no século XVII, praticamente devastaram as antigas civilizações aí existentes: em apenas trinta anos, os indios da ilha de Hispaniola foram completamente dizimados, a população do planalto mexicano decresceu em $90 \%$, 
Europa, e no Brasil do século XVIII, objetivando evitar os nocivos efeitos dessas ocorrências, que, a par de prejudicar a saúde da população e trazerIhe insegurança, diante do risco a que todos, indistintamente, ficavam expostos, atacavam a vitalidade econômica da localidade, inibindo seu desenvolvimento.

Caracterizavam-se, sobretudo, pelo exercício do poder de polícia, ainda que em caráter mínimo, próprio do Estado Liberal.

Bem retratam isso, por exemplo, os fatos que culminaram na famosa "Revolta da Vacina", irrompida em 1904, no Rio de Janeiro. Todos hão de lembrar que, incumbido Oswaldo Cruz da missão de exterminar, na antiga capital do País, a febre amarela, a qual comprometia a cidade, eclodiram ataques de políticos, da imprensa e até mesmo do povo, nas ruas, secundado por jovens militares nos quartéis, desferidos sob o ideal da liberdade absoluta. Consideravam eles monstruosa a campanha desfechada pelo governo (liberal), que, a par de submeter, forçosamente, a população aos vacinadores, os quais, de casa em casa, acompanhados de policiais, submetiam 0 povo à incisão da vacina, violando a incolumidade do seu corpo, interditavam as habitações malsãs, tão-somente com o fito de eliminar o mosquito transmissor e, com isso, erradicar a doença. ${ }^{(11)}$

Essa é, à evidência, a perfeita fotografia do nascimento de um Estado Social, em meio ao liberalismo vigente, o qual se apresentava cego, muitas vezes, aos reclamos de um interesse público mais abrangente do que aquele simplesmente decorrente de maior eficiência econômica.

Só após isso a política sanitária evoluiu para o patamar atual, o qual, sem desprezar seu conteúdo anterior, incorporou o conceito de cidadania à sua concepção; isto é, não apenas ampliou-se o âmbito do poder de polícia, adequando-o ao novo leque de missões do Estado - o que se deu mediante o advento de novas normas constitucionais e de direito administrativo dedicadas aos problemas sanitários -, mas, também, passou-se a admitir como aplicável à matéria a disciplina do Código de Defesa do Consumidor, que, em linhas gerais, reconhece ser direito básico a proteção à saúde e à segurança, contra os riscos decorrentes do consumo, e o direito a uma informação clara sobre produtos e serviços e a participação da gestão pluralística do Conselho de Saúde, na forma da Lei n. 8.142/90.(12)

de 25 milhões para 1,9 milhão de habitantes, caindo, nos Andes, de 10 milhões, em 1530, para 1,5 milhão sessenta anos depois (WACHTEL, N. Os índios e a conquista espanhola. História da América Latina. São Paulo: EDUSP, 1997, p. 200).

(11) Não se pode negar, no entanto, que, não houvesse o Poder Público sido tão imprudente a ponto de iniciar a campanha sem um prévio esclarecimento à população, mas fazendo-o em moldes similares aos determinados por uma lei prussiana de 1874 e aos praticados em Havana, Cuba, em 1900, quando os norte-americanos, após pesadas baixas em razão da doença, extirparam, em seis meses, o mosquito transmissor da doença, não teriam sido tão tumultuosos os fatos ocorridos (CALMON, P. Histórioa do Brasil. $2^{2}$ ed. São Paulo: José Olímpio editor, 1963, p. 2136).

(12) Enuncia o art. $1^{9}, \S 2^{2}$, da Lei n. 8.142/90: "O Conselho de Saúde, em caráter permanente e deliberativo, órgão colegiado composto por representantes do governo, prestadores de serviço, 
Referiu Foucault, uma vez, que "o controle da sociedade sobre os indivíduos não começa pela consciência ou pela ideologia, mas começa no corpo, com o corpo". ${ }^{(13)} \mathrm{Em}$ sua concepção, pois, a saúde, representada pela medicina, habitualmente controlada por uma elite, nada mais seria do que um instrumento de poder de um grupo sobre outros.

Se assim é, bem se vê, portanto, o quanto a forma atual de Estado mudou o enfoque dado à questão da saúde pública, em especial por via do controle sanitário: se antes as camadas dominantes deixavam de se dedicar aos problemas sanitários aflitivos de determinadas camadas sociais, atuando, quase exclusivamente, nos portos, em decorrência de aspectos fortemente embasados em critérios econômicos, não pode deixar o Poder Público, atualmente, de atender aos reclamos da população e estender sua atuação a outros segmentos, que não os mencionados.

Na medida, porém, em que intenta implementar o direito social à saúde da forma mais ampla, é inevitável seu contraste, cada vez mais agudo e freqüente, com a liberdade dos indivíduos, empresas ou inúmeros outros organismos sociais.

Afinal, é pela vigilância sanitária, versada nos arts. 197 e 200, II, da Constituição, ${ }^{(14)}$ que se controla não apenas a produção de bens e serviços de saúde, como, outrossim, as tecnologias pertinentes às áreas da medicina (medicamentos, soros, vacinas, equipamentos), estética (cosméticos, perfumes etc.), higiene, alimentos (inclusive processos de produção e circulação em todas as etapas), drogas veterinárias, agrotóxicos, lazer e serviços (hotéis, clubes, restaurantes, cabelereiros etc.), educação e convivência (escolas, creches, asilos, orfanatos, presídios e outros espaços de aglomeração urbana), meio ambiente (v.g. sistemas de abastecimento de água potável, proteção de mananciais, do solo, controle da poluição, coleta de lixo, sistemas de esgotos e resíduos sólidos, cemitérios etc.), ambiente de trabalho etc.

É por via dessa ação estatal, portanto, que se pode impedir um tabagista de fumar em determinados locais, submeter uma empresa à vistoria de suas instalações para verificação da adequação do ambiente de trabalho, processo de produção, comercialização etc., ou mesmo promover campa-

profissionais da saúde e usuários, atua na formulação de estratégias e no controle da execução da politica de saúde na instância correspondente, inclusive nos aspectos económicos e financeiros, cujas decisões serão homologadas pelo chefe do poder legalmente constituído em cada esfera do governo".

(13) FOUCAULT, M. O Nascimento da Clínica. Rio de Janeiro: Forense, 1980, p. 80.

(14) $O$ art. 197 da CF atribui ao Poder Público a função de dispor, nos termos da lei, sobre a regulamentação, fiscalização e controle das ações e serviços de saúde (competência legislativa); o art. 200, II, incumbe o Sistema Único de Saúde de executar as ações de vigilância sanitária, epidemiológica e da saúde do trabalhador (competência executiva). 
nhas de vacinação em massa, almejando a prevenção de doenças. Em todos esses casos, evidentemente, prevalece, como reflexo dos ditames do Estado Democrático de Direito, o interesse social, ao qual deve ceder o direito do indivíduo.

Isso, por óbvio, não implica que se possa descambar no arbítrio e solapar as liberdades individuais de modo inteiramente desconectado com a razoabilidade e a proporcionalidade que devem ter as ações do Poder Público. Tampouco importa total impossibilidade da atuação do particular em aspectos de interesse para a saúde. ${ }^{(15)}$ Significa, isso sim, a necessidade de adequação da conduta social a parâmetros legalmente prefixados, instituídos para a salvaguarda da sociedade e, assim, do próprio indivíduo, que, inexoravelmente, deve, então, submeter-se ao poder de polícia.

Como esclarece o art. 78 do Código Tributário Nacional, ${ }^{(16)}$ que busca delimitar a compreensão jurídica do poder de polícia, seu escopo é, mediante a limitação ou disciplina de direito, interesse ou liberdade, regular a prática de ato ou abstenção de fato, em razão de interesse público concernente à segurança, higiene, ordem, costumes, disciplina da produção e do mercado, exercício de certas atividades econômicas, tranqüilidade pública e respeito à propriedade e direitos individuais ou coletivos.

Objetiva, portanto, em poucas palavras, conter o abuso de direito por parte do indivíduo que, sob o argumento de ser livre, turba, de modo consciente ou não, direito alheio, principalmente quando, coletivo ou difuso, somente seria defensável, de outra forma, por meio do direito de ação, em especial a civil pública, ${ }^{(17)}$ quase sempre exercida posteriormente ao dano que procura evitar.

Impõe-se, dessa forma, que o Poder Público se atenha tão-somente à sua finalidade básica - a proteção do interesse público sob essas variadas formas -, situação, decerto, excludente de eventuais desvios de poder, e proceda a esse mister em estrita consonância com o quanto determinado nos mandamentos legais, que, por supostamente traduzirem a vontade popular, constituem os únicos veículos adequados à implantação de restrições.

Essa, enfim, é a conduta compativel com os clássicos princípios constitucionais da legalidade e da democracia, os quais, em conjunto com o da

(15) Tanto que, segundo o art. 199 da Constituição e art. $4^{2}, \S 2^{2}$, da Lei n. $8.080 / 90$, pode a iniciativa participar do Sistema Único de Saúde de modo complementar.

(16) Lei n. 5.172, de 25.10.1966.

(17) Conforme art. $1^{9}$, IV, da Lei n. 7.347, de 24.7.1985, que trata, sem prejuizo da ação popular (versada no art. $5^{\circ}$, LXXIII, CF), da tutela dos direitos difusos e coletivos em geral, a despeito de específicas previsões com relação ao meio ambiente (I) e consumidor (II). 
igualdade, ${ }^{(18)}$ também informativo dessa atividade, constituem o esteio do Estado Democrático de Direito pretendido por nossa Constituição.

\section{BIBLIOGRAFIA}

ABBAGNANO, N. Dicionário de Filosofia. $4^{\mathrm{a}}$ ed. São Paulo: Martins Fontes, 2000.

BOBBIO, N.; MATTEUCCI, N. e PASQUINO, G. Dicionário de Política. $5^{\mathbf{a}}$ ed. Brasília: UnB. São Paulo: Imprensa Oficial do Estado de São Paulo, 2000, vol. 2.

CALMON, P. História do Brasil. 2ª ed. São Paulo: José Olímpio editor, 1963, vol. 6.

CANOTILHO, J. J. G. Constituição Dirigente e Vinculação do Legislador. $2^{\underline{a}}$ ed. Coimbra: Coimbra Editora, 2001.

FOUCAULT, M. O Nascimento da Clínica. Rio de Janeiro: Forense, 1980.

HESSE, K. Elementos de Direito Constitucional da República Federal da Alemanha. Tradução da 20ª ed. alemã, de Luis Afonso Heck. Porto Alegre: Fabris, 1998.

KUJAWSKI, Gilberto de Mello. Ortega y Gasset - A Aventura da Razão. São Paulo: Moderna, coleção Logos, 1994.

REALE, M. Filosofia do Direito. $5^{\mathrm{a}}$ ed. São Paulo: Saraiva, 1969.

SALDANHA, N. O Estado Moderno e a Separação de Poderes. São Paulo: Saraiva, 1987.

WACHTEL, N. Os índios e a conquista espanhola. História da América Latina. Org.: Leslie Bethell. São Paulo: EDUSP, 1997, vol. 1.

(18) Tanto sobre o prisma material como formal. 